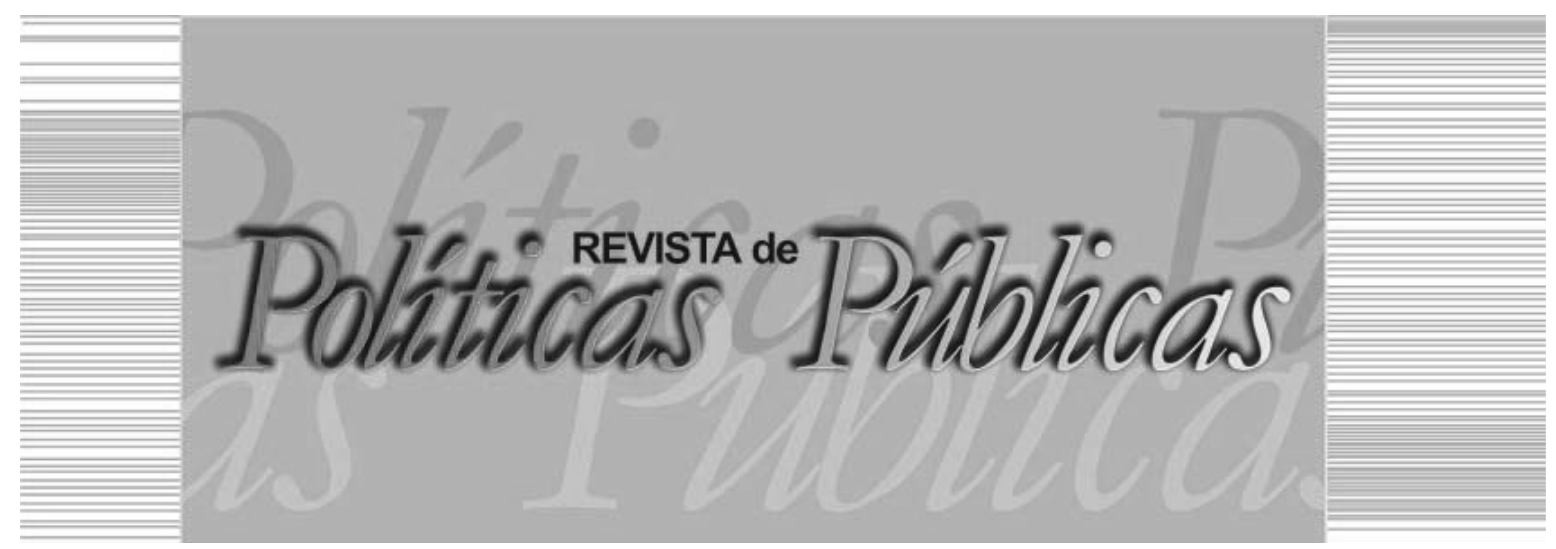

\title{
RESERVA DE VAGAS NAS INSTITUIÇÕES DE ENSINO: reflexões sobre a verificação de fenótipo para os autodeclarados pretos e pardos
}

\author{
Reijane Pinheiro da Silva \\ Cássia Araújo Moraes Braga ${ }^{2}$
}

\section{Resumo}

Este artigo apresenta reflexões sobre a repercussão da Orientação Normativa $n^{\circ}$ 3, de agosto de 2016, do Ministério do Planejamento, Desenvolvimento e Gestão (MPDG), que estabelece diretrizes para a verificação da autodeclaração de candidatos que pleiteiam o ingresso no ensino superior ou em concurso público pelo sistema de ação afirmativa para pretos e pardos. Por meio da pesquisa documental, especificamente dos editais de vestibulares dos Institutos Federais, constatou-se que alguns Institutos criaram as comissões de verificação com a atribuição de confirmar, via análise fenotípica, se a autodeclaração corresponde à verdade. A Orientação Normativa, além de violar os direitos estabelecidos na convenção 169 da OIT, da qual o Brasil é signatário, desrespeita o Estatuto da Igualdade Racial e reifica um argumento teoricamente superado no âmbito das teorias antropológicas, qual seja, o conceito de raça como determinante das diferenças humanas.

\footnotetext{
Bacharel em Ciências, Doutora em Antropologia Social pela Universidade Federal do Rio Grande do Sul (UFRGS), Professora Adjunta III da Universidade Federal do Tocantins (UFT). E-mail: reipinheiro@mail.uft.edu.br / Endereço: Universidade Federal do Tocantins - UFT: Quadra 109 Norte, Avenida NS15, ALCNO-14 - Plano Diretor Norte, Palmas - TO, 77001-090

2 Assistente Social, Mestranda em Desenvolvimento Regional pela UFT, Assistente Social no Instituto de Educação, Ciência e Tecnologia do Tocantins (IFTO). E-mail: cassia moara@hotmail.com / Endereço: Quadra 310 Sul, Lo 5, s/n - Plano Diretor Sul, Palmas - TO, 77.021-090.
} 
Palavras-chave: Cotas para pretos e pardos, autodeclaração, Comissões de verificação.

\title{
RESERVATION OF VACANCIES IN THE INSTITUTIONS \\ OF TEACHING: reflections on phenotype verification for the self-declared blacks and browns
}

\begin{abstract}
This article presents reflections on the repercussion of the Normative Orientation no. 3, of August of 2016, of MPDG, that establishes guidelines for the verification of the candidates self-declaration that they plead the entrance in the higher education or in call for tender for the system of affirmative action for blacks and brown. Through the documental research, specifically of the edicts of college entrance exams of the Federal Institutes, it was verified that some Institutes created the verification commissions with the attribution of confirming, through phenotypic analysis, if the self-declaration corresponds to the truth. The Normative Orientation, besides violating the established rights in the convention 169 of OIT, of which Brazil is signatory, disrespects the Statute of the Racial Equality and reify theoretically an argument overcome in the extent of the anthropological theories, which is, the race concept as decisive of the human differences

Key words: Quotas for blacks and brown, self-declaration, verification Commission.
\end{abstract}

\section{INTRODUÇÃO}

A reserva de vagas tenta corrigir a exclusão étnico-racial em nossa sociedade, uma vez que após a abolição da escravidão, não se implementou no país políticas públicas para incluir a população negra na educação e no mercado de trabalho. Alguns questionamentos sobre a Lei de Cotas são frequentemente apresentados, entre eles estão: Como identificar quem é negro em um país tão miscigenado como o Brasil? As cotas não representariam discriminação ao negro, sugerindo que o mesmo não é capaz de acessar a educação profissional e superior? Como evitar fraudes ao sistema de cotas?

Com base nesses questionamentos, internalizados e reproduzidos pela mídia e também pela nova conjuntura posta ao sistema de cotas por meio da Orientação Normativa ${ }^{\circ} 3$, de $1^{\circ}$ de agosto de 2016, do Ministério do Planejamento, Desenvolvimento e Gestão (MPDG), é que se construiu a proposta deste artigo. Cabe ressaltar que a polêmica em relação à seleção dos cotistas sempre se relacio- 
RESERVA DE VAGAS NAS INSTITUIÇÕES DE ENSINO: reflexões sobre a verificação de fenótipo para os autodeclarados pretos e pardos

nou ao fato de como seria essa identificação. Com base nisso, os próprios formuladores da lei não estabeleceram como definir quem é branco ou negro, deixando para quem se candidata apresentar sua autodeclaração.

Com a aprovação da Lei de Cotas em 2012, que torna obrigatória a reserva mínima de vagas para pretos, pardos, indígenas, alunos de escolas públicas e de baixa renda em instituições federais de ensino, as instituições que ainda não adotavam nenhuma política inclusiva precisaram se adaptar aos critérios da lei. Antes da aprovação da lei, várias instituições de ensino já adotavam a reserva de vagas. A Universidade de Brasília (UnB), por sua vez, estabeleceu em 2004 como critérios de análise para acesso à reserva de vagas, a averiguação do fenótipo do candidato. A instituição das comissões de verificação pela UnB causou um intenso debate nos meios acadêmicos e na sociedade em geral. Um caso em especial ganhou destaque: o fato de irmãos gêmeos terem sido diferentemente classificados fenotipicamente. Um foi considerado negro e o outro não, e a polêmica se deu pelo fato de serem gêmeos idênticos ${ }^{1}$. Parte da imprensa brasileira, que claramente se posicionava contra as cotas, explorou o fato, difundindo teses de que essas e outras políticas produziriam um país dividido entre negros e brancos e entre ricos e pobres, desconsiderando que essa já é uma realidade facilmente identificada no Brasil.

Em 2016, o debate em torno da necessidade de verificação fenotípica ganhou outro capítulo com a publicação da mencionada Orientação Normativa $n^{0} 3 / 2016$, que estabelece diretrizes para a verificação da autodeclaração de candidatos às vagas de concursos públicos, tendo como amparo legal a Lei $\mathrm{n}^{\circ} 12.990$, de 9 de junho de 2014. No entendimento do Supremo Tribunal Federal (STF) é necessária a verificação do fenótipo do candidato a reservas de vagas para evitar as fraudes, má-fé e não deslegitimar a política. (BRASIL, 2012). A orientação prevê ainda que as formas de verificação deverão considerar somente aspectos fenotípicos do candidato, os quais serão atestados obrigatoriamente com a presença do mesmo.

Desse modo, com o objetivo de compreender essa conjuntura atual sobre a lei de cotas no Brasil, apresentaremos uma reflexão sobre o processo de implantação desta lei. Para isso, identificamos as discussões realizadas nas primeiras universidades que instituíram as ações afirmativas e o embate político que perpassa esse processo, 
utilizando de revisão bibliográfica e análise documental. Para identificarmos o impacto da Orientação Normativa citada, analisamos vinte e sete editais de cursos técnicos dos Institutos Federais de cada estado brasileiro, no primeiro semestre de 2017. Entre os Institutos que não adotam a seleção unificada, analisamos os editais dos Campi localizados nas capitais brasileiras.

\title{
2 A POLÊMICA DAS COTAS PARA PRETOS E PARDOS NAS INSTITUIÇÕES DE ENSINO
}

No debate sobre as cotas e considerando a especificidade de temática, foi no âmbito da antropologia brasileira que o tema mobilizou o maior número de teóricos. Com posicionamentos muitas vezes divergentes, as contribuições problematizam temas como legitimidade da política, miscigenação e impactos.

Conforme Oliven (2007), o termo Ação Afirmativa relaciona-se com o ato de proteger minorias e grupos que já foram alvo de discriminação, por meio de um conjunto de políticas públicas a fim de remover barreiras que impeçam o acesso à educação, ao mercado de trabalho e posições de liderança.

As cotas para acesso ao mercado de trabalho existem no Brasil desde a Lei no 8.213 , de 24 de julho de 1991, que dispõe sobre a obrigatoriedade de contratação de pessoas com deficiência em empresas privadas. Em 2006 foram apresentados dois manifestos ao Congresso Nacional que argumentavam sobre a questão de políticas afirmativas. O primeiro, intitulado de Todos têm direitos iguais na República Democrática, argumenta sobre o princípio da igualdade política e jurídica dos cidadãos, afirmando que a Lei de Cotas feria este princípio e que poderia aumentar o racismo:

\begin{abstract}
Os signatários do manifesto apontam como caminho para o combate à exclusão social a construção de serviços públicos universais de qualidade em todos os setores importantes como educação, saúde, etc. Meta a ser alcançada "pelo esforço comum de cidadãos de todos os tons de pele contra privilégios odiosos que limitam o alcance do princípio republicano da igualdade política e jurídica”. (OLIVEN, 2007, p. 41).
\end{abstract}

Já o segundo manifesto, intitulado de Manifesto a favor da Lei de Cotas e do Estatuto da Igualdade Racial, argumenta que a Lei de Cotas combateria a desigualdade racial no Brasil. O referido manifesto baseia-se em estudos que afirmam que os negros apresentam 
RESERVA DE VAGAS NAS INSTITUIÇÕES DE ENSINO: reflexões sobre a verificação de fenótipo para os autodeclarados pretos e pardos

menor escolaridade, piores condições de moradia, maior taxa de desemprego em comparação aos brancos e asiáticos. Além disso, o documento menciona que a ascensão social no Brasil ocorre por meio do acesso ao ensino superior, e que jovens negros que concluem o Ensino Médio, que em certa medida são vítimas do racismo e não têm o mesmo poder aquisitivo e oportunidades de jovens brancos, não conseguem acessar os cursos mais seletivos das universidades públicas. (OLIVEN, 2007).

Outra discussão apresentada pelo autor versa sobre a dificuldade de se identificar quem é negro no Brasil, uma vez que a miscigenação seria um dos processos fundamentais na formação identitária nacional. Desdobrando o debate, Oliven (2007) menciona que a autodeclaração poderia permitir que muitos se aproveitassem das oportunidades abertas pela reserva de vagas de forma imprópria, sabotando o processo, com declarações falsas. Por outro lado a criação de comissões para verificação daria um poder perigoso ao Estado, abrindo as possibilidades de reforçar a valorização de traços fenotípicos como suficientes para classificar racialmente os indivíduos. Para além dessa discussão é preciso considerar que o racismo no Brasil é cotidiano e institucional e que, neste sentido, não é difícil identificar quem é negro, ou seja, é fácil identificar para discriminar, violentar e muitas vezes matar. Neste contexto, as ações afirmativas caracterizam-se como uma reparação a danos causados pela história de exclusão de pretos e pardos, escravidão e pelo processo de abolição que criou outras formas de opressão. A introdução de políticas de cotas tem um caráter emancipatório e transformador e poderá promover, a longo prazo, mobilidade social, mais equidade e justiça, além de valorizar os vários elementos da cultura africana presentes na cultura brasileira.

A Assembleia Legislativa do Rio de Janeiro aprovou em 2001 a Lei $\mathrm{n}^{\mathrm{o}}$ 3708, de 9 de novembro de 2001, que instituiu cota de até quarenta por cento para a população negra e parda no acesso à Universidade do Estado do Rio de Janeiro (UERJ) e à Universidade Estadual do Norte Fluminense. Esse processo provocou um denso debate entre os antropólogos brasileiros. Entre eles, Maggie e Fry (2004) argumentaram que a adoção de cotas como política de Estado foi pensada de cima para baixo, e que substituíram o conceito de um país composto de raças misturadas por um país de raças distintas. Os autores pontuam que é o preconceito que reproduz desigualdades. Afirmam ainda que o que resolveria a desigualdade seria a reserva 
de vagas para os pobres e não somente para os negros. Consideram que a população branca e pobre, que assim como a negra, não teve acesso a um ensino de qualidade, ficando também excluída da universidade. O cerne da discussão proposta por Maggie e Fry (2004) é a possibilidade das cotas reforçarem a representação da ideia de raça, incentivando conflitos raciais, classificando a população por meio do fenótipo, reforçando segregações ao invés de superá-las.

Esses autores não são contra a correção de desigualdade de ordem racial, no entanto, pensam que as políticas de ações afirmativas se submetem à classificação racial bipolar. Eles enfatizam que outras medidas poderiam ser adotadas como colocar escolas públicas de melhor qualidade em periferias, entretanto, afirmam que essas medidas custariam caro para o governo, ao contrário do custo zero com as cotas.

De acordo com Munanga (2004), discutir cotas para negros nas universidades é uma questão problemática, uma vez que não é fácil definir quem é negro no Brasil. Pelos estudos da genética, muitos brasileiros brancos apresentam marcadores genéticos africanos. Além disso, os conceitos de negro e de branco têm um fundamento político e ideológico, mas não biológico. Desse modo, é uma qualificação política que é utilizada na definição de negro no Brasil. Antes de se discutir cotas é preciso, segundo o autor, avaliar a sua aplicação em outros contextos, pensar políticas de inclusão social dos negros e pobres e melhorar a educação básica.

De acordo com Carvalho (2003), discutir cotas é repensar a função da universidade pública, que deveria formar líderes que representam a diversidade étnica e racial do país. $\mathrm{O}$ autor cita que em um país com $47 \%$ de população de negros, o percentual de estudantes negros no ensino superior não passa de $12 \%$, e de professores, menor que $1 \%$. Desse modo, para o autor, a proposta de cotas tira a tranquilidade da elite branca da universidade.

Com base nisso, Carvalho (2001) afirma que com o decreto do governador e da Câmara Estadual do Estado do Rio de Janeiro, a UERJ (Universidade do Estado do Rio de Janeiro) e a UENF (Universidade Estadual do Norte Fluminense) adotaram, a partir do processo seletivo de 2003, a reserva de vagas para alunos egressos de escola pública e alunos afrodescendentes, impossibilitando que as mesmas universidades sejam abertas somente ao mercado dos cursinhos: 
RESERVA DE VAGAS NAS INSTITUIÇÕES DE ENSINO: reflexões sobre a verificação de fenótipo para os autodeclarados pretos e pardos

[...] Não podemos separar o ingresso nas universidades do mercado dos cursinhos. A vaga do vestibular no Brasil tem um valor. A não ser em casos muito excepcionais, podemos até chegar a descobrir quanto custa uma vaga numa universidade brasileira: em tempo e em dinheiro. (CARVALHO, 2001, p. 14).

Carvalho (2001, p. 16) pontua que a grande questão para a implantação das ações afirmativas nas universidades é o convencimento dos professores, pois os mesmos têm o poder de reproduzir a elite brasileira: "[...] é preciso compreender o racismo acadêmico e este somente pode ser compreendido na classe dos professores universitários e na maneira como eles se comportam diante do racismo brasileiro".

Para embasar seu argumento, Carvalho (2001) menciona que no ano 2000, a Câmara dos Deputados fez um levantamento e este revelou que o Distrito Federal tinha $63 \%$ da sua população de pretos e pardos, sendo que a Universidade de Brasília tinha na época 1400 professores, sendo 14 negros, correspondente a $1 \%$. Com isso, quem irá decidir se os negros poderão ter reservas de vagas nas universidades serão brancos. O autor pontua que as pessoas são contra as cotas porque ao reservarem vagas para negros, vão diminuir as vagas para brancos, e consequentemente, haverá perda de privilégios. Desse modo, as propostas de inclusão racial serão decididas por $99 \%$ de professores brancos.

Esse mesmo autor menciona que a história da academia brasileira foi marcada de obstáculos ao ingresso de intelectuais negros. Que os brancos são beneficiados por viver em uma sociedade racista. São muitos privilégios que os permitem ter mais vantagens e concentrar mais recursos. Desse modo, "[...] o Estado Brasileiro, respeitoso da autonomia universitária, ainda não sabe com detalhe desse perfil racial dramático, porque esse mesmo estado é controlado quase exclusivamente por membros da elite branca que construiu a nossa academia." (CARVALHO, 2003, p. 313).

O racismo ${ }^{2}$ brasileiro se sustenta nos discursos que celebram a mestiçagem e silenciam a condição de negro no Brasil. Esses discursos disseminados defendem que o Brasil é diferente dos Estados Unidos e a África do Sul, pois aqui existem raças separadas, pois teríamos a pluralidade de identidades raciais em um convívio harmônico. Carvalho (2003) enfatiza o fato de não compararem o grau de integração racial do Brasil com o alcançado pelos referidos pa- 
íses, como por exemplo, o número de juízes, médicos, professores universitários negros, a fim de analisarem a participação de negros nos processos decisórios. Com isso, a proposta das ações afirmativas é deselitizar o ensino superior público, para possibilitar que a universidade pública não seja mais de uma só cor e classe.

\section{CRITÉRIOS ADOTADOS PARA SELEÇÃO DOS \\ CANDIDATOS AUTODECLARADOS PRETOS E}

PARDOS: o caso UnB e a Orientação Normativa de 2016

Os amparos legais das ações afirmativas para acesso às Instituições de Ensino são a Lei $n^{0}$ 12.711, de 29 de agosto de 2012, a Portaria Normativa $\mathrm{n}^{\circ} 18$, de 11 de outubro de 2012 e o Decreto ${ }^{\circ}$ 7.824 de 11 de outubro de 2012. Nos três documentos é mencionado que as instituições federais de educação superior e de ensino técnico de nível médio deverão destinar $50 \%$ de suas vagas para estudantes que tenham cursado integralmente o ensino médio em escolas públicas. Desses $50 \%$, a metade deverá ser destinada aos estudantes com renda per capita igual ou inferior a um salário mínimo e meio. No art. $3^{\circ}$ da Lei $n^{\circ} 12.711 / 2012$ determina que as vagas reservadas serão preenchidas, por curso e turno, por estudantes autodeclarados pretos, pardos e indígenas e por pessoas com deficiência. (BRAISL, 2012).

Desse modo, com a aprovação da Lei de Cotas em 2012, as instituições que ainda não adotavam nenhuma política inclusiva tiveram de fazer uma adaptação aos critérios da lei: "Antes da aplicação da lei, 31\% (18 de 58) não possuíam nenhuma política dessa natureza. A lei tornou obrigatória a adoção dessas políticas por todas as universidades." (FERES JUNIOR et al., 2013, p. 11).

Siqueira (2004) pontua que a primeira versão do projeto de cotas da UnB foi em 1999, por meio de um texto enviado pelos professores José Jorge de Carvalho e Rita Laura Segato, ambos do Departamento de Antropologia, que foi apresentado em um evento do Núcleo de Estudos Afro-Brasileiros (NEAB/UnB). Os participantes do evento, em sua maioria, reagiram de forma negativa à proposta: "[...] Os que apoiaram o texto, na verdade, o viam mais como possibilidade de levantar a discussão sobre o racismo do que propriamente como uma proposta exeqüível ou viável de ação afirmativa." (SIQUEIRA, 2004, p. 174). 
RESERVA DE VAGAS NAS INSTITUIÇÕES DE ENSINO: reflexões sobre a verificação de fenótipo para os autodeclarados pretos e pardos

Em consonância, Carvalho (2005) também contextualiza o processo para aprovação de cotas para negros e índios na UnB. O autor afirma que a proposta de cotas na UnB surgiu em resposta política a um caso de conflito racial ocorrido no Departamento de Antropologia da referida universidade, o Caso Ari. Esse caso refere-se a Arivaldo Lima Alves, o primeiro estudante negro a entrar no doutorado de antropologia da UnB. O estudante foi reprovado em uma matéria obrigatória por motivos inaceitáveis, o que o colocou na iminência de perder o curso de doutorado. Após dois anos de luta e retaliações, a UnB reconheceu a injustiça cometida e obrigou o Departamento de Antropologia a mudar a nota na disciplina. Além do Caso Ari, outro incidente ocorreu com um grupo de estudantes negros em 2001, quando os mesmos foram hostilizados pelos seguranças de uma festa de estudantes também da Antropologia. Em decorrência disso, esses estudantes se mobilizaram e exigiram da universidade uma reparação do ato de racismo por meio de um Fórum, em que debateram a questão racial na universidade.

Desse modo, Carvalho (2005), que vivenciou toda essa polêmica na UnB, pontua que a questão não é saber se os antropólogos defendem ou não a autoclassificação, e sim saber se realmente estão envolvidos na luta antirracista. $\mathrm{O}$ referido autor cita que recebeu pouco apoio dos antropólogos a favor da discussão sobre as cotas e muito menos dispostos a garantir a permanência de estudantes negros na universidade.

Conforme Siqueira (2004), outra iniciativa que possibilitou a implantação das ações afirmativas na UnB foi o projeto A cor da Bahia, o qual realizou o primeiro censo universitário no Brasil, por meio de aplicação de um questionário no ato da matrícula no primeiro semestre de 2000 na Universidade Federal da Bahia (UFBA), Universidade Federal do Rio de Janeiro (UFRJ), Universidade Federal do Paraná (UFPR), Universidade Federal do Maranhão (UFMA) e Universidade de Brasília (UnB). Os dados favoreceram uma análise sobre a correlação entre o racismo e seu impacto no ingresso de estudantes nas universidades.

Com base nisso, em 2002, a discussão sobre a reserva de vagas para estudantes negros e indígenas já estava consolidada. Em 2003 foi solicitado um Plano de Metas aos professores Carvalho e Segato, a fim de que o projeto de ações afirmativas fosse implementado na UnB. Esse Plano foi levado para aprovação do Conselho 
de Ensino, Pesquisa e Extensão (CEPE) da UnB, e após sete reuniões, correspondendo a um ano e meio de discussões, foi formada a Comissão para Implementação do Plano de Metas (CIPM). Essa Comissão teve momentos de desacordo sobre o percentual de $20 \% \mathrm{e}$ sobre a fiscalização nas inscrições para evitar fraudes:

Muitas formas de fiscalização foram sugeridas, desde entrevistas -
medida considerada ideal, mas inviável economicamente, segundo
duvidável avaliação do Vice-reitor - até o uso de fotografias - na-
quele momento, pensado apenas como um agente constrangedor
em casos de fraude deliberada. O projeto original não detalhava
esse quesito mas, nas discussões e textos subseqüente, tanto de
José Jorge de Carvalho e Rita Laura Segato, havia ficado claro que
o único critério de atribuição de cor politicamente aceitável seria a
auto-identificação (SIQUEIRA, 2004, p. 180).

Siqueira (2004) argumenta que essa forma de análise foi inspirada na experiência da Universidade Estadual do Mato Grosso do Sul (UEMS), por ser uma ação com um custo baixo e de fácil implementação. Essa proposta consistia na formação de uma comissão responsável pela análise das fotografias dos candidatos às reservas de vagas: "A proposta, até onde se sabe, não foi fundamentada em outro princípio, senão o de evitar fraudes. E, sobretudo não consta que haja por trás dela qualquer 'inspiração científica', biológica ou de qualquer outra natureza." (SIQUEIRA, 2004, p. 181).

Em relação a isso, Carvalho (2005, p. 244) se posiciona contra as fotos nos processos seletivos da UnB afirmando que as mesmas "[...] despolitizam o posicionamento do sujeito ao transferir a responsabilidade de assumir sua condição racial para a comissão". E espera que paremos de naturalizar esse escândalo a fim de realmente beneficiar os negros deste país pela primeira vez. Por fim, o autor afirma que o critério das fotos foi implantado devido à baixa participação de antropólogos no processo de discussão e implementação das ações afirmativas na UnB.

Sobre essa polêmica do critério de análise das fotos, temos algumas discussões jurídicas a respeito. Na Medida cautelar em Arguição de Descumprimento de Preceito Fundamental 186-2, redigida pelo Ministro Gilmar Mendes do STFl em 31 de julho de 2009, a qual foi proposta pelo Partido Político Democratas (DEM), contra atos administrativos da Universidade de Brasília que instituíram o programa de cotas raciais para ingresso naquela universidade, menciona que a propositura se deu em função do partido acreditar que 
RESERVA DE VAGAS NAS INSTITUIÇÕES DE ENSINO: reflexões sobre a verificação de fenótipo para os autodeclarados pretos e pardos

cotas violam o princípio da igualdade e dignidade humana, já que não é possível identificar a que raça pertence uma pessoa. (BRASIL. 2009). O partido argumenta que para definir raça do candidato vai muito além de fenótipos individuais, e que a aparência da pessoa diz pouco de sua ancestralidade. Afirma que a reparação do dano causado pela escravidão não pode ser aplicada em um país miscigenado como o Brasil.

Desse modo, o relator, ao fazer um estudo sobre as categorias raça, genoma humano e preconceito racial, afirma que no Brasil nunca houve uma segregação racial como nos Estados Unidos, porém, no Brasil, desenvolveu-se uma forma de discriminação racial com base na cor da pele da pessoa, diferentemente dos Estados Unidos, onde o preconceito é com base na origem do indivíduo.

A Arguição menciona ainda que a UnB, ao adotar o sistema de cotas, estabeleceu como critério a análise por fenótipo do candidato. Com base nisso, o relator afirma que este critério gera alguns questionamentos, pois não sabemos bem qual seria o fenótipo de pretos e pardos brasileiros; também não há técnica ou capacitação para definir quem é branco ou preto. Por esse motivo, a própria UnB já se equivocou na referida análise ao afirmar que gêmeos idênticos são de raças diferentes, assim como outros exemplos mencionados na Arguição. Com isso, o relator aponta, ainda, que este critério de analisar fenótipo suscita diversos problemas, e por essa razão, várias universidades adotam somente o critério da autodeclaração associado à renda.

O relator chama a atenção para as possíveis consequências da adoção de políticas de ações afirmativas que considerem somente o critério racial, no entanto, sugeriu um aprofundamento sobre essas questões e indeferiu o pedido de suspensão de matrículas de alunos cotistas da UnB, uma vez que considera que enquanto as mudanças apontadas pelo partido não acontecem, devem-se aprimorar e fortalecer ações que visam diminuir a desigualdade no Brasil.

Já na Arguição de Descumprimento de Preceito Fundamental 186, tendo como relator Ricardo Lewandowski do STF, do dia 26 de abril de 2012, menciona-se como louvável a iniciativa da UnB ao supervisionar e fiscalizar as declarações dos candidatos às vagas reservadas, com o intuito de atender as finalidades da Lei de cotas. Com isso, conforme a Arguição, evita fraudes e abusos, ao contrário de negar o valor antropológico para afirmação de identidades. 
Assim, indica que este modelo da UnB seja adotado pelos sistemas inclusivos do território nacional. Há muitos questionamentos de que essas comissões poderiam, por usar critérios como o do fenótipo, suscitar o preconceito e discriminação, ou ainda usar de arbitrariedades. Entretanto, essas comissões são necessárias, no entendimento do STF, uma vez que as autoridades devem se pautar por critérios razoavelmente objetivos, evitando a fraude e má-fé e não deslegitimar a política.

Com base nesse argumento, em julho de 2016, o Ministério Público Federal (MPF) do Distrito Federal oficiou alguns Institutos Federais solicitando informações sobre a verificação como procedimento para seleção da reserva de vagas para os candidatos autodeclarados como pretos ou pardos. Solicitou, ainda, nome, Cadastro de Pessoa Física (CPF) e fotografia colorida dos autodeclarados que se matricularam nos cursos da instituição de ensino.

Além disso, o MPDG publicou a Orientação Normativa $\mathrm{n}^{\circ} 3$, de $1^{\circ}$ de agosto de 2016, que estabelece as formas como verificação dos candidatos que se autodeclaram pretos e pardos para as vagas de concursos públicos. Prevê que as formas de verificação deverão considerar somente aspectos fenótipos do candidato, os quais serão verificados obrigatoriamente com a presença do candidato.

Assim, para fazer uma análise de como os Institutos Federais de Educação, Ciência e Tecnologia estão selecionando os candidatos para a reserva de vagas, principalmente analisando quais os Institutos que adotam as Comissões de Verificação, considerando somente aspectos fenótipos dos candidatos que se autodeclaram pretos ou pardos, fizemos um levantamento dos editais para os cursos Técnicos Subsequentes dos Institutos Federais de cada Estado Brasileiro. Nos Institutos que não adotam a seleção unificada foram analisados os editais dos Campi localizados nas capitais brasileiras. Foram analisados vinte e sete editais para seleção de candidatos para os cursos Técnicos Subsequentes para o primeiro semestre de 2017.

Dos vinte e sete editais dos Institutos analisados, somente cinco Institutos Federais mencionaram em seus editais sobre a análise de fenótipos para candidatos que se autodeclararem pretos e pardos. Os referidos Institutos estão localizados nos seguintes estados: Amapá, Amazonas, Mato Grosso do Sul, Roraima e Tocantins. Pode-se observar que alguns Institutos consideram somente a autodeclaração 
RESERVA DE VAGAS NAS INSTITUIÇÕES DE ENSINO: reflexões sobre a verificação de fenótipo para os autodeclarados pretos e pardos

do candidato, conforme o item 5.7 do Edital do Instituto Federal de Educação, Ciência e Tecnologia da Paraíba:

\begin{abstract}
A indicação de pertencimento às etnias preta, parda ou indígena para participação no sistema de cotas para autodeclarados Pretos, Pardos e Indígenas (PPI) independe de quaisquer comprovações documentais, valendo tão somente a afirmação do próprio candidato no ato de inscrição e, no ato da pré-matrícula, a assinatura de um termo no qual se autodeclarará pertencente à etnia. (INSTITUTO FEDERAL DE EDUCAÇÃO, CIÊNCIA E TECNOLOGIA DA PARAÍBA, 2016, p. 22).
\end{abstract}

Em contrapartida, conforme os itens 3.3 e 3.4 do edital do Instituto de Roraima, o candidato à reserva de vagas que se autodeclara preto ou pardo deve participar de uma entrevista gravada em áudio e vídeo:

3.3 A verificação da veracidade da autodeclaração acontecerá por meio de entrevista, conforme cronograma do ANEXO I, gravada em áudio e vídeo e considerará, tão somente, os aspectos fenotípicos do candidato. 3.4 A autodeclaração do candidato, o registro em áudio e vídeo de sua entrevista e o parecer da Comissão de Verificação terão validade apenas para este certame. (INSTITUTO FEDERAL DE EDUCAÇÃO, CIENCIA E TECNOLOGIA DE RORAIMA - CAMPUS AMAJARI).

Os editais que mencionam essa verificação, afirmam que será considerado o fenótipo dos candidatos. No caso do Instituto Federal do Tocantins (IFTO), o candidato pode ser desclassificado do processo seletivo se houver unanimidade entre os integrantes da Comissão de Análise Socioeconômica e de Reserva de Vagas do IFTO quanto ao não atendimento do quesito cor ou raça por parte do(a) candidato(a). É válido destacar que esta análise é feita por meio de uma foto colorida $3 / 4$.

O Estatuto da Igualdade Racial (Lei $\mathrm{n}^{0} 12.288$, de 20 de julho de 2010) define a população negra como o conjunto de pessoas que se autodeclaram pretas ou pardas. Com base nisso, em 11 de setembro de 2016, a Associação Brasileira de Antropologia (ABA) publicou uma nota de repúdio à Orientação Normativa ${ }^{\circ} 3$, de $1^{\circ}$ de agosto de 2016, do MPDG, que estabelece diretrizes para a verificação da autodeclaração de candidatos às vagas de concursos públicos, tendo como amparo legal a Lei $\mathrm{n}^{\circ} 12.990$, de 9 de junho de 2014. $\mathrm{Na}$ nota afirma que a redação da Orientação Normativa revela que 
o Estado manifesta seus interesses de forma repressiva, suspeitando sobre a índole e legitimidade dos interesses dos cidadãos.

A ABA afirma que ao determinar comissões para analisar a veracidade da autodeclaração, considerando apenas aspectos fenotípicos do candidato, nega-se o domínio de identidades que não podem ser constatadas por critérios exclusivamente objetivos e sim com base nas trajetórias individuais e coletivas, e que só podem ser experimentadas e não analisadas externamente. (ASSOCIAÇÃO BRASILEIRA DE ANTROPOLOGIA, 2016). Nesse sentido a Orientação Normativa promoverá situações de constrangimento, repressão e discriminação por cor de pele, em vez de promover igualdade e liberdade. Assim, definir a identidade de sujeitos sociais com base em achismos apresenta práticas reificadoras da existência de raças. Em conformidade com a nota de repúdio, cor ou raça se relaciona mais com construções individuais e coletivas de caráter identitário, do que de aspectos fenótipos. Com isso, a ABA se posiciona a favor da autodeclaração livre de suspeitas.

\section{CONCLUSÃO}

Se o discurso para não implementação da Lei de cotas estava relacionado ao fato de que no Brasil não se pode identificar quem é branco ou negro em função da miscigenação, então, por que devem ser avaliados os fenótipos dos candidatos às reservas de vagas? $\mathrm{A}$ reserva de vagas não se trata apenas de um direito e sim de oportunizar o que sempre foi negado. Refere-se à equidade e reconhecimento de que temos uma sociedade excludente, em que negros e indígenas não tiveram as mesmas oportunidades do que os brancos.

$\mathrm{O}$ discurso contrário à reserva de vagas, internalizado pela sociedade, fundamenta-se em casos de fraudes, afirma que as cotas podem gerar mais discriminação e que os negros são capazes de acessarem as vagas em instituições públicas sem a necessidade de cotas. Esse discurso desconsidera que se o país oferecesse uma educação pública equiparada com a do ensino privado, se os cursinhos preparatórios fossem gratuitos e se diminuísse a desigualdade social ao ponto de crianças e adolescentes não serem forçadas a trabalhar para ajudar suas famílias, os jovens negros e pardos teriam as mesmas chances de entrar na universidade que os jovens brancos. A nosso ver, esse discurso está mais preocupado com as vagas que a classe dominante estaria perdendo, do que no fato de que as cotas 
RESERVA DE VAGAS NAS INSTITUIÇÕES DE ENSINO: reflexões sobre a verificação de fenótipo para os autodeclarados pretos e pardos

podem aumentar a discriminação aos negros e indígenas. Os casos de fraudes, assim como em diversas outras políticas públicas, devem ser averiguados pela justiça e não por comissões de verificação.

Vale ressaltar que os editais analisados não mencionam a técnica para identificar quem é branco ou negro, talvez seja pelo fato de que não há técnica específica para isso. Assim, seria arriscado passar essa responsabilidade para servidores, que, olhando a cor da pele, o formato do nariz, da boca, a cor do cabelo, deveriam afirmar com toda certeza quem é branco ou negro em um país misto como o Brasil. Desse modo, consideramos louvável o posicionamento de alguns institutos federais que, em seus processos seletivos, respeitam a autodeclaração dos candidatos, cabendo assim, em caso de denúncia, a justiça investigar se foi fraude ou não. Os mesmos respeitam a Convenção no 169 da Organização Internacional do Trabalho (OIT), da qual o Brasil é signatário, a qual foi convocada em Genebra em 1989.

Essa Convenção aplica-se aos povos tribais, em que as condições sociais, culturais e econômicas os distingam de outros setores da coletividade nacional, e aos povos indígenas, os quais conservam suas próprias instituições sociais, econômicas, culturais e políticas, ou parte delas. $\mathrm{O}$ artigo $1^{\circ}$ dessa Convenção menciona que o critério fundamental para determinar os grupos é a própria consciência de identidade indígena ou tribal, ou seja, o respeito à autodeclaração dos mesmos. No artigo $2^{\circ}$ afirma que os governos deverão assumir a responsabilidade para efetivar os direitos sociais, econômicos e culturais desses povos, respeitando a sua identidade social e cultural.

O que queremos enfatizar com essa reflexão, é que a contextualização histórica da implantação das ações afirmativas não se resume nas fraudes ou comissões de verificação, mas sim no papel da universidade na reprodução do racismo, o motivo de ter poucos estudantes e professores negros, os currículos eurocêntricos e na exclusão racial dentro da universidade.

\section{REFERÊNCIAS}

ASSOCIAÇÃO BRASILEIRA DE ANTROPOLOGIA. Repúdio à Orientação Normativa $n^{\circ} 3$, de $1^{\circ}$ de agosto de 2016, contra o Programa de Promoção da Igualdade Racial. Belo Horizonte, 2016. Disponível em: <http://conflitosambientaismg.lcc.ufmg.br/noticias/nota-daassociacao-brasileira-de-antropologia-aba/>. Acesso em: 22 jan. 2017. 
BRASIL. Lei n. 12.711, de 29 de agosto de 2012. Dispõe sobre o ingresso nas universidades federais e nas instituições federais de ensino técnico de nível médio e dá outras providências. Diário Oficial da União, Brasília, DF, 2012.

. Supremo Tribunal Federal. Acórdão Arguição de Descumprimento de Preceito Fundamental $n^{\circ} 186$. Diário de Justiça Eletrônico, Brasília, DF, 26 abr. 2012. Ministro Enrique Ricardo Lewandowski, Disponível em:<http://redir.stf.jus.br/paginadorpub/ paginador.jsp?docTP=TP\&docID=6984693 > . Acesso em: 19 jan. 2017.

. Supremo Tribunal Federal. Medida Cautelar em Arguição de Descumprimento de Preceito Fundamental no 186. Diário de Justiça Eletrônico, Brasília, DF, 31 jul. 2009. Ministro Gilmar Mendes. Disponível em:<www.stf.jus.br/arquivo/cms/noticiaNoticiaStfArquivo/ anexo/ADPF186.pdf>. Acesso em: 19 jan. 2017.

CARVALHO, J. J. de. As Ações Afirmativas como resposta ao racismo acadêmico e seu impacto nas ciências sociais brasileiras. Teoria e Pesquisa, n. 42/43, p. 303-340, jan./jun. 2003. Disponível em: $<$ http:// www.redeacaoafirmativa.ceao.ufba.br/uploads/ufscar_artigo_2003_ JJdeCarvalho.pdf > . Acesso em: 1 abr. 2017.

. As propostas de cotas para negros e o racismo acadêmico no Brasil. Revista Sociedade e Cultura, Goiânia, v. 4, n. 2 p. 1330, 2001. Disponível em:<https://www.revistas.ufg.br/fchf/article/ viewFile/514/465>. Acesso em: 1 abr. 2017.

. Usos e abusos da antropologia em um contexto de tensão racial: o caso das cotas para negros na UNB. Horizontes Antropológicos, Porto Alegre, ano 11, n. 23, p. 237-246, jan./jun, 2005. Disponível em: $<$ http://www.scielo.br/scielo.php?script=sci_arttext\&pi $\mathrm{d}=$ S0104-71832005000100018 $>$. Acesso em: 7 mar. 2017.

FERES JÚNIOR, J. et al. Levantamento das políticas de ação afirmativa (GEMAA): o impacto da Lei $\mathrm{n}^{\circ} 12.711$ sobre as universidades federais. Rio de Janeiro: IESP-UERJ, set. 2013. Disponível em: $<$ http://gemaa.iesp.uerj.br/levantamentos/o-impacto-dalei-no-12-711-sobre-as-universidades-federais-2013/>. Acesso em: 11 jan. 2017.

INSTITUTO DE PESQUISA ECONÔMICA APLICADA; FÓRUM BRASILEIRO DE SEGURANÇA PÚBLICA. Atlas da Violência. Rio de Janeiro, jun. 2017. Disponível em: $<$ http://www.ipea.gov.br/ atlasviolencia/download/2/2017>. Acesso em: 20 jan. 2018. 
RESERVA DE VAGAS NAS INSTITUIÇÕES DE ENSINO: reflexões sobre a verificação de fenótipo para os autodeclarados pretos e pardos

\section{INSTITUTO FEDERAL DE EDUCAÇÃO, CIÊNCIA E}

TECNOLOGIA DA PARAÍBA. Edital nº 63/2016. Processo Seletivo para os cursos Técnicos Subsequentes ao Ensino Médio (Pós-Médio) PSCT 2017. João Pessoa, 2016.

INSTITUTO FEDERAL DE EDUCAÇÃO, CIENCIA E TECNOLOGIA DE RORAIMA - CAMPUS AMAJARI. Edital $\mathrm{n}^{\circ}$ 03/2016. Estabelece normas para o processo seletivo de educação profissional dos cursos técnicos integrados ao ensino médio integral e de alternância, oferecidos pelo Campus Amajari do Instituto Federal de Educação, Ciência e Tecnologia de Roraima - IFRR, referente ao ano letivo de 2017.1. Amaraji, 2016.

MAGGIE, Y.; FRY, P. A reserva de vagas para negros nas universidades brasileiras. Estudos Avançados, São Paulo, v. 18, n. 50, p. 67-80, jan./abr. 2004. Disponível em: $<$ http://www.scielo.br/scielo. php? script $=$ sci_arttext\&pid=S0103-40142004000100008>. Acesso em: 12 jan. 2017.

MUNANGA, K. A difícil tarefa de definir quem é negro no Brasil. Revista Estudos Avançados, São Paulo, v. 18, n. 50, p. 51-66, 2004. Disponível em: $<$ http://www.scielo.br/scielo.php?script=sci_arttext\&pi $\mathrm{d}=$ S0103-40142004000100005>. Acesso em: 1 abr. 2017.

OLIVEN, A. C. Ações afirmativas, relações raciais e política de cotas nas universidades: uma comparação entre os Estados Unidos e o Brasil. Educação, Porto Alegre, ano XXX, v. 30, n. 1, p. 29-51, jan./abr.,2007. Disponível em: $<$ http://revistaseletronicas.pucrs.br/ojs/index.php/faced/ article/view/539>. Acesso em: 11 jan. 2017.

SIQUEIRA, C. H. R de. O processo de implementação das ações afirmativas na Universidade de Brasília (1999-2004). O público e o privado, Fortaleza, n. 3, jan./jun. 2004. Disponível em: $<$ http://www. seer.uece.br/?journal=opublicoeoprivado\&page=article\&op=view\&pat h\%5B $\% 5 \mathrm{D}=276>$. Acesso em: 7 mar. 2017.

\section{Notas:}

1 Notícia veiculada na Revista Veja. (Disponível em: $<$ http://veja.abril.com.br/blog/reinaldo/ veja-4-materia-de-capa-raca-nao-existe/>).

2 De acordo com a Atlas da Violência de 2017, lançado pelo Instituto de Pesquisa Econômica Aplicada (Ipea) e pelo Fórum Brasileiro de Segurança Pública, a cada 100 pessoas assassinadas no Brasil, 71 são negras. E que as principais vitimas são homens, jovens, negros e de baixa escolaridade, um retrato do racismo brasileiro. 
